\title{
Evolution in its Course.
}

$\mathrm{O}$ $\mathrm{NE}$ of the most persistent plaints of the antievolutionist is that the biologist has failed to demonstrate to the satisfaction of the unbeliever the actual occurrence of evolution in the presentday world. The criticism is difficult to meet, for, apart from the blind eye which the critic is apt to turn to the well-meaning efforts of the biologist, evolution is a slow process not readily to be caught in its stride. Even amongst biologists themselves there has been a tendency in recent years to look askance at the work of the systematist, and to lean upon the experiments of the laboratory as the only sure test of biological processes.

It is well to be reminded, therefore, that the last decade has seen a great advance in the technique of the systematist, and that the advance has afforded new ground for the examination of the problem of evolution in natural conditions. In the old days an account of the bird-life of a limited area in California would have meant little more than the bare records of a local list of the bird inhabitants, but, under the new analysis, Mr. Joseph Grinnell's "Distributional Summation of the Ornithology of Lower California" (Univ. California Pub. Zool., vol. 32 , No. 1, 1928, pp. 1-300) becomes a plea for the recognition of evolution in its course.

Two factors have made for this progress in method. The first is the attention given to the discernment of minute differences in form, and it is sufficient answer to those who cavil at the difficulties of the determination of sub-species, that in these barely recognisable differences lie the critical, formative stages, which may lead to the development of easily distinguished species. The second factor lies in the attempt to associate these minute differences of sub-species with the peculiar conditions of environment in which each is situated, in an endeavour to discover something of the causes and essential conditions of the differentiation.

The general results of the analysis of the birdlife of California show, then, the progress of evolution in Nature, as closely as the examination of static conditions can be expected to interpret a continuous process. They do not reveal anything that is particularly novel or unexpected, but the fact that they are based upon an intensity of examination and detail of comparison such as was unavailable to Darwin or Wallace, lends them new weight and authority.

In the first place, there is evidence of gradual differentiation. Among the numerous races of Californian birds, examples can be selected showing practically every appreciable stage in differentiation, from neighbouring stocks showing departures from a type so slight that they can be appreciated only when a long series of individuals is averaged, to full-blooded species, sharply distinct, no longer crossing with related species, judging from the absence of wild hybrids.

In the second place, the differentiation, that is, the variational move towards species, is not everywhere a uniform process. The inequality may be associated with several definite characters of the environment. Thus, in many of the groups of wide distribution, the amount of difference shown by the geographical races varies directly with the degree of spatial separation. Take the clear case of the group including the California linnet (Carpodacus). The group extends over the mainland, a distance north and south of some eight hundred miles, and in that space has three recognisable subspecies. But on Los Coronados Islands, only seven miles off shore, there is another race, appreciably but not constantly or conspicuously different. Forty miles from the nearest mainland, on the San Benito Islands, there are greater and fairly constant differences from the birds of the mainland, and on Guadalupe Island, 135 miles away, the differences are so great and constant that the form there is designated a full species.

The differences themselves are significant. The Guadalupe birds are distinguished by their larger size, longer legs, relatively shorter wings, and shorter keel of sternum - indications of a loss of wing power, which suggest a step towards the flightlessness of some other birds on remote Pacific islands.

Even a slight water barrier may be influential as an effective form of isolation, preventing free interbreeding of birds from neighbouring places. Although there are no apparent barriers in the whole extent of the mainland of lower California, long distance has had the same isolating effect, allowing differentiation in remote stocks despite commingling over adjacent territory.

Other cases of the influence of isolation, such as that shown by the spotted towhee (Pipilo maculatus), could be cited; they illustrate the fact that closely similar races in a series are not situated "within the same differentiation area, nor yet in remote differentiation areas, but in separate and adjacent differentiation areas."

In the third place, it becomes clear that environment may have an effect which, no matter that the subjects of its influence are different, results in a remarkably similar set of results. A very peculiar climatic condition exists between the crest of the Sierra San Pedro Mártir and the Pacific, where a region of meagre rainfall has a high atmospheric humidity - a humid desert. Various birds in this region, as different as flycatchers, finches, and woodpeckers, show similar modifications, especially marked in deeper coloration, certain proportions of wing and tail, lesser size of bill, and so on. Subjection of very different stocks to the same peculiar set of critically important conditions has brought parallel modifications in certain functions and structures.

This suggests that the inherited variations have not been random, but have been directed. So far so good, but the author goes on to say that subspecific characters are therefore to be regarded, either intrinsically in themselves or in their linkages, as of worthy sorts in the racial struggle for existence -not, ordinarily, indifferent or useless ones. Here he seems to travel in advance of his facts, for it has

No. 3102, Vor. 123] 
yet to be shown that the common characters which have been induced by a peculiar environment in so many different kinds of birds can have an equal survival value to each of these birds of habits so different. On the facts put thus, the safer assumption would seem to be that similar conditions induce a similar organic reaction irrespective of 'worthiness ' or ' unworthiness.'

After all, unworthiness in the evolutionary sense is not likely to survive in hard competition with worthiness, and Mr. Grinnell finally reaches a Darwinian conclusion. "The accumulating evidence of the field naturalist is bringing conviction that the incipient species in nature, the subspecies, owes its origin to a process, on a vast scale, of trial, discard, and preservation, of individuals, and of groups of individuals comprising populations, which populations from generation to generation are thereby rendered more nearly adjusted to such environments as they can endure at all. But environments themselves never stabilize; they are changing, proliferating, evolving continually. A balanced state of perfect adaptation of the organism can never be attained, but only continually approached, such approach being forced, under penalty of extinction." J. R.

\section{Physical Foundations of Chemical Theory.}

$\mathrm{N}^{0}$ task is more difficult for the chemist of the present day than that of trying to keep abreast with those advances in atomic physics which affect him so closely that he cannot ignore (even if he cannot hope fully to understand) them. Sidgwick's book on " The Electronic Theory of Valency," which was reviewed at length in these columns last year (April 7, 1928, vol. 121, p. 527), provided a partial solution of the problem from the chemist's point of view; but the brief monograph of Lessheim and Samuel referred to below ${ }^{1}$ may be regarded as a complementary contribution of unrivalled value from the physical side. The professional spectroscopist does not often realise how difficult his subject can be made for the lay reader, and it is a common experience, even when reading books or lectures of a semi-popular character, to be pulled up short by technical or controversial details of which no explanation is given or attempted.

In the more leisurely days of the past, there was usually ample time for one fundamental idea to be grasped before attention was distracted by the next new development. Progress was then made by the orderly passing of the ball from one three-quarter back to another, until it was safely placed behind the goal, and in due course 'converted.' from speculation or hypothesis to theory. Now, however, the ball progresses amid the confusion of a wild 'forward' rush, in which the casual onlooker can only occasionally get a glimpse of the ball, and has but little chance to observe the effects of individual play, whilst even the professional reporter is in danger of overlooking essential points in the game. Thus, whereas Bohr's 'principal quantum number' $n$ had a sufficient start to secure universal acceptance, and has retained its strictly integral character, it has been followed in the works of subsequent authors by a trail of subsidiary numbers, which are in open competition with one another, and (to add to the confusion) appear at some stage to have undergone a process of 'disintegration' whereby integral quanta have been resolved into proper fractions.

The difficulties arising from such causes as these

${ }^{1}$ Die Valenzzahl und ihre Beziehungen zum Bau der Atome. Von Hans Lessheim und Rudolf Samuel. (Fortschritte der Chemie, Physik und physikalische Chemie, herausgegeben von A. Eucken, Band 19, Heft 3.) Pp. 98. (Berlin: Gebrüder Borntraeger, 1927.) 6.40 gold marks. are in large measure removed by the careful and concise exposition of Messrs. Lessheim and Samuel, and it is a high compliment to their skill that we can claim to have been able to understand and to make use of the major portion of their.monograph. It was, indeed, only on reaching the tenth section of the book that it became necessary to add a marginal comment, "I cannot follow this," and to call in the help of a professional physicist to explain in fuller detail the complex behaviour of systems with several outer electrons. The elaborate spectroscopic analysis of sections 12 and 13 was also too complicated to be understood at one reading, but it would be difficult to praise too highly the way in which the spectroscopic evidence is used in order to provide a sure foundation for definite chemical deductions; and it is one of the conspicuous merits of the book that this evidence is set out in such a convincing way, that its validity is no longer open to question even by the most extreme type of 'sceptical Chymist.'

Much of the charm of the quantum theory of the present day arises from the introduction, by Goudsmit and Uhlenbeck in 1925, of the conception of the spinning electron. This conception has, indeed, done more than anything else to bring order out of the chaos of subsidiary quantum numbers, and thus to restore to Bohr's theory some semblance of the simple and logical character which it possessed in 1913. From the chemical point of view, the principal merits of this early quantum theory was the provision of a logical basis for the valency theories of Kossel and Lewis, since it indicated the existence of groups of electrons with identical ' principal quantum numbers' $n=1,2,3$, 4,5 , etc., corresponding with the $K, L, M, N, O$, etc., levels of the X-ray spectra of the elements. In this way it explained the inertness of the noble gases, and the ionisation of adjacent elements such as the halogens and the alkali metals, as depending on the exceptional stability of certain completed groups of electrons. Since, however, the theory gave no clue to the number of electrons in each quantum group, these numbers must logically have followed the Rydberg series, with $2,8,8,18,18$, and 32 electrons in successive levels, corresponding with the number of 'cells' which Langmuir postulated in successive layers or 'shells' of his static atomic model. 